\title{
Which One is the Best Safe Haven During the Special Time, Bitcoin or Gold?
}

\author{
Juncheng $\mathrm{Luo}^{1, *}$ \\ ${ }^{1}$ Department of Chongqing number 1 secondary school, Chongqing, China \\ *Corresponding author: guanghua.ren@gecacademy.cn
}

\begin{abstract}
The outbreak of COVID-19 in 2019 has had a huge impact on the global economy while also threatening people's lives and property. In this context, investment means and ideas have also undergone great changes, such as a shift from riskier investments to more prudent ones. Traditional investment means such as gold, emerging investment means such as bitcoin. In this paper, gold and bitcoin are taken as the research objects, and the relevant risks and policy status quo are reviewed and analyzed. The research results show that gold is more suitable for investment in abnormal economic forms, while bitcoin has higher risks. On the one hand, the conclusion of this paper provides countermeasures for national financial development, and on the other hand, provides relevant suggestions for individual investors.
\end{abstract}

Keywords: Bitcoin, COVID-19, gold, risk, price, safe haven

\section{INTRODUCTION}

Since the COVID-19 epidemic, the global economy has declined a lot. In 2020, according to the data (https://data.worldbank.org.cn), the GDP growth rate of many countries around the world had been negative. For example, France has declined At $8.1 \%$, India fell by $8 \%$, Canada fell by $5.2 \%$, the European Union fell by $6.2 \%$, and North America fell by $3.7 \%$. And many companies, especially physical companies, have suffered huge losses or even went bankrupt. In the case of economic recession, people need so-called safe havens to prevent their assets from being affected. In the past 2020, we can see that the value of gold has increased very rapidly, reaching a peak of about 66 in September 2020 [1]. US dollars per gram, the price of gold in September 2019 is still 50 US dollars per gram. In fact, in the traditional sense, gold has always been a good safe-haven asset. We know that gold is a powerful hedging tool. Virtual currency has also become a hot topic in recent years, especially today. The price of Bitcoin has risen to $\$ 63,587.85$. Many scholars also regard Bitcoin as a safe-haven asset.

In previous studies, Onur Gozbasi1, Buket Altinoz, Eyup Ensar Sahin, and others, through Is bitcoin a sage haven? In a study on the factors that affect bitcoin prices, you can know the impact of bitcoin prices and various factors [2]. They concluded that only people who have a good understanding of Bitcoin recommend investing in Bitcoin. According to the research of Kris Osstheok and
Christian, cyber security threats to bitcoin exchanges: adversary exploitation and laundering techniques, they found that bitcoin actually has a big loophole in the network security [3]. Ahmet sensoy, brian M.Lucey, and Md Akhtaruzzaman researched whether gold was used as a safe haven during the new crown period and provided policymakers, regulators, and media with information about gold as a hedging tool and safe-haven asset during the new crown period [4]. Guidance. Liya A, Qian Qin, Hafiz Waqas Kamarn, Anusara Sawangchai, Worakamol Wosetsri, Mohsin Raza pointed out that the price of gold is related to many macro factors in their research on the impact of macroeconomic indexes on the price of gold [5]. In the study Bitcoin: an inflation hedge but not a safe haven, Sanyup Choi and Junyeok Skin found that the price of Bitcoin is very uncertain, and even many factors have nothing to do with the new crown epidemic. In this paper, the advantages and disadvantages of bitcoin and gold are analyzed, and finally, which asset is a better hedge tool is obtained after comparison.

\section{DATA AND METHOD}

$\begin{array}{ccc}\text { Data from the website } & \end{array}$ https://www.coindesk.com/price/bitcoin/

Basic information about Bitcoin: COINS is a kind based on the decentralized, using a peer-to-peer network and consensus initiative, open source, and the encryption of currency blockchain as the underlying technology, the 
currency by the hearing on October 31,2008 , in the published papers, on January 3, 2009, the foundation block was born, in some countries, the central bank, government agencies, academia is the currency as a virtual good, Bitcoin has three basic functions: transaction medium, unit of account and store of value. However, due to its high volatility, it does not have the latter two basic functions and therefore is not a currency

\subsection{Bitcoin}

\subsubsection{Risks}

As an example, the policies of three different regions are different. First, in mainland China, as early as 2013, the Chinese government issued a notice on preventing risks related to Bitcoin, declaring that Bitcoin would not be regarded as a settlement tool within the jurisdiction of the Chinese People's Government. Then, in 2014, the People's Bank of China issued an analysis saying bitcoin has five risks[6].

Policy risk: The decentralized nature of Bitcoin may threaten the traditional monetary system, affect the government's macro-control ability and reduce fiscal revenue; rich

Legal risks: Currently, Bitcoin is only a virtual commodity, not a currency, under the legal protection of various countries;

Speculative risk: Bitcoin is not guaranteed by national credit or real assets, and its price may fluctuate greatly, which is extremely risky for investors.

Money laundering risk: Bitcoin has the characteristics of anonymity and no geographical restrictions, and it is difficult to monitor the flow of funds, so it is very easy to evade government supervision;

Substitution risk: Bitcoin still has defects such as lack of credit guarantee, poor security performance and easy to lead to deflation. At the same time, it also has to face the competition of various later copycat coins, which has a large substitution risk

cyber risk: Bitcoin is gaining traction as another store of value. Its market cap surpasses all other cryptocurrencies on the market. But its high monetary value also makes it an attractive target for cyber criminals[7]. Hacking campaigns often target the weakest links in an ecosystem. In Bitcoin, these are the current trading platforms. Since each exchange breach can shave billions of dollars off bitcoin's market value, this poses a threat not only to the direct victims but to everyone who owns bitcoin.
Table 1. Bitcoin legal \& illegal

\begin{tabular}{|l|l|}
\hline Nicaragua & legal \\
\hline Argentina & legal \\
\hline Bolivia & illegal \\
\hline Brazil & legal \\
\hline Canada & legal/banking ban \\
\hline Colombia & legal/banking ban \\
\hline Russia & legal/banking ban \\
\hline Israel & legal \\
\hline
\end{tabular}

In Europe, such as Germany, the German government has recognized the legal and tax status of bitcoin, making it the first country in the world to officially recognize the legal status of bitcoin.

From this, we can see that bitcoin actually has a different status in different countries, so we need to consider the risk of bitcoin policy before considering whether it is a safe haven asset.

\subsection{2 the factor that influences the price of the bitcoin}

First of all, we look at the factors affecting the price of Bitcoin from the demand and supply sides. Generally, bitcoin is divided into trading demand and speculative demand[8]. From the perspective of speculative demand, the demand for Bitcoin is an investment or speculative tool. Investors can choose various investment methods, but investors should generate search costs when determining investment targets. The decision preferences of new investors are often distorted by social concerns (e.g., news media attention on Bitcoin), which are driven by heat-driven investment behaviors because they reduce the search cost information for potential investment opportunities. Under the glare of the news media, investment targets are likely to be the first choice for new investors[9].

Products, investors' attention to Bitcoin, and related reports in the news media have positively impacted investors' perception of Bitcoin. On the other hand, if society pays too much attention to bitcoin, it is likely to lead to "herd behavior." Therefore, I use proxy variables and investors' attention to Bitcoin to represent the speculative demand for bitcoin. The higher the level, the more investors' attention to bitcoin, and the lower the cost of bitcoin being identified as an investment object, the greater the speculative demand for bitcoin. In terms of liquidity transactions, bitcoin is actually rarely used as a currency for transactions, circulating only on a small number of websites and countries[10].

\subsubsection{1 availability}

Bitcoin is mined by independent miners who maintain the system and support the latest protocols. Miners are 
responsible for adding blocks to the system or approving transactions and receive a set amount of Bitcoin in return for each block they process. Each additional 210,000 blocks reduces the number of Bitcoin rewards by half, which is known as a "halving event."

In 2009, miners were awarded 50 bitcoins, 25 in 2013, 12.5 in 2018, and 6.25 in 2020. Because of the high equipment, power, and maintenance costs, bitcoin needs to maintain some value to motivate miners to keep digging. If the value of bitcoin falls too low, miners may stop mining or hold on until the value of bitcoin rises. Thus, Bitcoin's value is also likely to rise as demand increases.

\subsubsection{Valuation}

The market consists of buyers and sellers. Ideally, buyers and sellers should maintain a balance. That is, the buyer is willing to support a high enough price for a product that the seller agrees to sell its product.

Once more buyers are willing to buy bitcoin, the price is expected to be pushed up. In addition, the demand for Bitcoin is also affected by the number of payment platforms (such as PayPal, etc.) that accept Bitcoin as a payment method[11].

\subsubsection{Trader sentiment}

Some people hold bitcoin to pay for purchases, similar to how we use fiat money. Others may buy bitcoin for transactions. They hold bitcoins until their value rises and then convert them into dollars (or euros (or other currencies). The greater the number of convertible currencies is, the greater the potential for speculation and volatility is. In the case of the underlying asset, the holder is responsible for keeping the coins, paying maintenance fees and finding a buyer when it is ready to sell. Alternatively, traders can make commission-free, leveraged trades through CFDS while choosing to go long or short based on the movement of bitcoin's value[12].

\subsection{Gold}

In the traditional sense, gold has been a good hedging tool and safe-haven asset for so many years. Gold can be used as a good hedging tool, whether it is during the raging period of the new crown virus or the economic depression.

\subsection{1 the factor that impacts the price of gold}

The first is the influence of supply and demand on the price of gold. Because gold has the attributes of a commodity, it will be affected by the supply and demand relationship of commodities. When the supply of gold exceeds the demand, the price of gold will drop.
Otherwise, it goes up. The sources of gold include mineral gold, recycled gold, and the sell-off of gold reserves by central banks. The source of demand for gold is mainly jewelry demand, industrial demand, and investment demand. Among them, the demand for jewelry is the largest. Then there is the investment demand. Changes in investment demand will have a great impact on the fluctuation of gold prices. In addition, the large-scale purchase of gold by governments of various countries will also cause the price of gold to rise. In addition, the U.S. dollar also has an impact on the price of gold. Like other commodities, gold is denominated in U.S. dollars. Under other conditions unchanged, the depreciation of the U.S. dollar will increase the price of gold. When the U.S. dollar appreciates, the price of gold will fall. The U.S. dollar index and gold The price trend basically shows the opposite direction. The correlation coefficient between the two is negative, and this negative correlation is statistically significant, so sometimes, we can judge the trend of the gold price by the trend of the dollar price. In addition, inflation also has a certain impact on the price of gold. Inflation reflects the stability of a country's currency value and reflects the national currency's purchasing power. When the inflation level is low, the national currency value is relatively stable, so the currency's purchasing power is relatively high. Strong, when the inflation level is high, the purchasing power of the domestic currency will weaken, and consumers will lose confidence in the domestic currency when fighting fires, which will cause domestic consumers to be more willing to hold gold, which will cause the price of gold to rise. In addition, the international crude oil price also has a certain impact on the price of gold. However, since the price of international crude oil is also denominated in US dollars, the price of international crude oil is similar to the price of gold to a certain extent. There is also the impact of interest rates on the price of gold. Capital is profit-seeking, and the holding of gold does not earn any interest. The return on investment comes from the rise in the price of gold. When the interest rate level is relatively low, it is Holding gold will get a certain amount of income, especially when the Fed cuts interest rates, it will cause the US dollar index to fall, which will lead to an increase in the price of gold.

\subsubsection{Risks}

Now that the influencing factors of the gold price are known, the risk of the gold price is well analyzed. From five years ago to today, September 10, 2021, the price rose from 40,223.80 to 57,698.62. And from this chart, it can be seen that the price of gold is still in an upward trend most of the time, and the overall price is relatively stable without excessive fluctuations. Gold is actually an investment product with little risk. 


\section{CONCLUSION}

In general, by analyzing the influencing factors of Bitcoin and the price of gold, we can find that Bitcoin is actually a relatively high-risk product. Although its price is rising very high and very fast from a macro point of view, But in fact, its price is very unstable. Just a few days ago, the price of Bitcoin suddenly dropped by $\$ 1 \mathrm{w}$, so I prefer to regard Bitcoin as a high-risk and high-return speculative product. People can use its characteristics As a hedging tool, not a hedging tool. The price of gold is basically very stable. From the performance of the financial crisis in the 1990s to 2008, gold has always been regarded as a very effective hedging tool.

Bitcoin is a high-risk and high-return investment. Generally speaking, the best investment method is through fixed investment: buy some bitcoins every once in a while, do not care about the price, buy more and more, bear market hoard coins, bull market Profit.

\section{REFERENCES}

[1] Kris Oosthoek and Christian Doerr 2020 Cyber security threats to bitcoin exchanges: adversary expliotation and laundering techniques. https://ieeexplore.ieee.org/abstract/document/9300 238

[2] Rutger de Olde 2021 Bitcoin:safe haven for currencies in times of economic uncertainty. http://essay.utwente.nl/87450/

[3] Salisu,Afees and Raheem,Lbrahim and Vo,Xuan 2021 Assessing the safe haven property of the gold market during COVID-19 pandemic. https://www.sciencedirect.com/science/article/pii/S 1057521921000090

[4] Nikolaos A. Kyriazis 2020 Is bitcoin similar to gold? An integrated overview of empirical findings

https://www.mdpi.com/705514

[5] Kris Oosthoek, Christian Doerr 2020.From Hodl to Heist:analysis of Cyber Security Threats to Bitcoin Exchanges

https://ieeexplore.ieee.org/abstract/document/9169 412

[6] Dirk G. Baur, Thomas K. Mcdermott 2010. Is gold a safe haven? International evidence

https://www.sciencedirect.com/science/article/pii/S 0378426609003343

[7] Onur Gozbasi Nuh Naci Yazgan Oniversitesi 2021.Is bitcoin a safe haven? A study on the factors that affect bitcoin prices https://www.researchgate.net/publication/35320321 2_Is_Bitcoin_a_Safe_Haven_A_Study_on_the_Fac
tors_that_Affect_Bitcoin_Prices?_esc=publication CoverPdf\&el=1_x_3\&enrichId=rgreqf85c70472b694ea78acec152989e518eXXX\&enrichSource $=Y 292 Z X J Q Y W d 1 O z M 1 M z I$ wMzIxMjtBUzoxMDQ1ODE3MjU1MjkyOTMxQ DE2MjYzNTM2NzI0NjM\%3D

[8] Sangyup Choi Junhyeok Shin.2021 Bitcoin: an inflation hedge but no a safen.

https://www.sciencedirect.com/science/article/pii/S 1544612321003810

[9] Liya A Qian QIing and Hafiz Waqas Kamran Anusara Sawangchai Worakamol Wisetsri Mohsin Raza 2021 How macroeconomic indicators in fluence gold price management?

https://www.emerald.com/insight/content/doi/10.1 108/BPMJ-12-2020-0579/full/html

[10] Ahmet Sensoy Brian M. Lucey 2021.Is gold a hedge or. A safen-haven asset in the COVID-19 crisis? https://www.researchgate.net/publication/35281679 9_Is_gold_a_hedge_or_a_safehaven_asset_in_the_COVID19_crisis?enrichId=rgreqf26c30829ec9439dc81e79f7cc5bedefXXX\&enrichSource=Y292ZXJQYWdlOzM1Mjgx Njc5OTtBUzoxMDM5OTc4Njc1MDQ4NDQ4QD E2MjQ5NjE2NDYyMjI\%3D\&el=1_x_3\&_esc=pu blicationCoverPdf

[11] Fangda Sun 2019.An analysis of factors influencing the price of bitcoin.

https://scholarworks.calstate.edu/concern/theses/7s $75 \mathrm{df} 638$

[12] Xingchun Wang 2021.The values and incentive effects of options on the maximum or the minimum of the stock prices and market index.

https://www.sciencedirect.com/science/article/pii/S 1062940820302345 